\title{
Chemical Challenge Agent
}

National Cancer Institute

\section{Source}

National Cancer Institute. Chemical Challenge Agent. NCI Thesaurus. Code C158326.

A challenge agent comprising a non-radioactive chemical or elemental substance. 